https://doi.org/10.48009/1_iis_2013_300-306

Issues in Information Systems

Volume 14, Issue 1, pp.300-306, 2013

\title{
A FRAMEWORK FOR AN INTERACTIVE WEB-BASED APPLICATION COURSE
}

\author{
Paul J. Kovacs, Robert Morris University, kovacs@rmu.edu \\ John J. Scarpino, Robert Morris University, scarpino@rmu.edu \\ Wenli Wang, Robert Morris University,wangw@rmu.edu
}

\begin{abstract}
This paper outlines a framework appropriate for use for the teaching of a course requiring the analysis, design, implementation and software testing of a project based interactive Web-based application. This framework can be useful for integrating a number of essential knowledge, skills, and abilities or competencies learned in a typical Information Systems program of study. These essential competency clusters include programming principles, database management, systems analysis and design, web technologies, and project management. Also delineated is software testing, which has grown in the past decade, especially in the area of tool development that improves testing capabilities
\end{abstract}

Keywords: CIS Curriculum, Web-based application, Software Development Lifecycle and Software Testing

\section{INTRODUCTION}

This paper presents a framework for teaching a project driven interactive Web-based application in a Computer and Information Systems curriculum. A Web-based application is chosen due to the necessity for students to learn about web-based applications in order to gain sufficient relevant technical skills to compete in the job market [6]. This framework can be useful for integrating a number of essential knowledge, skills, and abilities or competencies learned in an Information Systems program of study. As a result, the course framework described in this paper combines programming principles, database management, Web technologies with the major principles of systems analysis and design and the tools, techniques, and procedures necessary for software testing. The course is proposed to be a required course for Computer Information Systems majors who have completed course work in introductory Web design, computer programming, database design, and systems analysis and design, project management and Quality Issues Information Technology.

\section{LEARNING ENVIRONMENT}

The purpose of this course framework is to analyze, design and deploy an interactive (database driven) Web-based application in a team environment during one academic semester. To accomplish this, it is necessary to have a Web development environment consisting of Web server software, Web server based programs, database software, and web authoring/site management software. Additionally, the appropriate classroom and hardware are necessary.

\section{Software}

The selection of the Web server software is a necessary component for this Web-based application. This can determine the database base selection, the web authoring and site management software, and the programming language. From a market position point-of-view, ASP.NET is used by approximately $20 \%$ of public web sites utilizing a known server-side programming language. It is second only to PHP at 78.9\%. Java is used for a serverside programming $4.1 \%[8]$.

Many large corporations, including several in author's area, choose to use ASP.NET rather than PHP for their web applications in order to reduce dependencies on open source technologies and take advantage of support that they may already receive from Microsoft (or other traditional vendors). Furthermore, by this point their studies; students may have taken a Visual Studio course (Visual Basic or C\#) with and exposure to ASP.NET so this platform is used by the authors for this Web-based application. Additional software has included a Web authoring/site management 


\section{Issues in Information Systems}

Volume 14, Issue 1, pp.300-306, 2013

tools such as Microsoft Expression Web as well as Graphic design software such as Adobe Photoshop or Macromedia Fireworks.

\section{Classroom/Hardware}

The recommended teaching and learning environment is a computer laboratory. Specifically, this environment should include a permanently mounted overhead projection system, instructor's station equipped with a microprocessor, and student workstations configured as a LAN. Each student workstation or at least one workstation should have Web server software installed and running. In the case of the authors computer laboratory, all workstations have Visual Studio installed allowing each student to run ASP.NET. Additionally, the authors have the use a department Web server running IIS and a Web server running Linux/Apache.

\section{PREREQUISITE COURSES}

The intent of this framework is not to teach HTML, ASP.NET, programming, data base design or any of the other essential competencies learned in other courses. Rather, the purpose is to allow the student to make use of these skill sets to design and deploy database driven Web-based application.

\section{Introductory Web Design}

Introductory Web design courses many times only teach web-authoring software such as Microsoft Expression Web Designer or Adobe Dreamweaver. Although these WYSIWYG editors allow for Rapid Application Development, they also generate the HTML and cascading style sheets (CSS) for the Web designer. Students with only competencies in these or similar software packages may have difficulty when required to debug a Web page or embed JavaScript. In order works, students should have a working knowledge of HTML and CSS. Furthermore, students should not only know how to position HTML and CSS elements but also how to organize web page designs, control the visibility and presentation of HTML layers, and write client-side scripts in JavaScript.

\section{Web-based Programming Language}

To develop a fully interactive Web-based application that request special processing on a Web server such as database queries or handling form data, a program running on a Web server must accept and process data. Therefore, it is necessary for the student to have prior instruction in a course that focuses on object-oriented programming and design. There are a number of languages available for server-side programming (Java, Perl, C\#, Visual Basic) and it is simply a matter of choosing the language that best serves your needs. Before you decide on what language to use, you should consider the following:

- the server platform

- the server software you run

- previous experience in programming

- the database you have chosen for your backend

The operating system will determine the language you choose. Microsoft Windows and POSIX-compliant Unix-like systems will most likely be your two main choices in technology. Once the Operating System is chosen, the next choice is your server software. On Windows systems, you have IIS which comes installed for free with windows. Many of the web servers commonly used on Portable Operating System Interface or POSIX-compliant Unix-like systems are available for Windows too, including the very popular and well-respected Apache web server.

\section{Database Management Systems}

Relational database technology is an essential component for this Web-based application and students need more than a limited exposure to database systems as taught in many introductory IS courses using Microsoft Office. 


\section{Issues in Information Systems}

Volume 14, Issue 1, pp.300-306, 2013

Students need to have been exposed to a course that provides experience with database design and implementation based on a thorough analysis of requirements and information modeling. Prior exposure for the student should include hands-on experience with the design of and interaction with a database management system and use standard Structured Query Language (SQL).

\section{Systems Analysis and Design}

Students need to be exposed to the theories and practices of Systems Development Life Cycles (SDLC). They should understand the fundamental topics such as systems theory, the role of the information system in operating and managing the organization, and systems analysis and design concepts. The purpose, function, and expected outcomes of each phase and activity of the systems development life cycle (SDLC) should be discussed from both theoretical and practical perspectives. Specific design techniques, such as data flow diagrams and data dictionaries, are discussed and used. Other topics include the function of design tools such as CASE, planning techniques, and project management. This course should also include case studies and hands-on experiences. Especially students should be educated on the importance of clarifying the deliverables at the end of each phase of the life cycle and understanding how to set up measurable outcomes from the analysis and design activities.

\section{Software Testing}

In order to achieve the high assurance quality, many organizations are infusing Software Testing (ST) and Software Quality Assurance (SQA) throughout the Software Development Life Cycle (SDLC). SQA is defined as the functional entity performing software quality assessment and measurement [5]. The IEEE Standard 12207 defines QA as "a process for providing adequate assurance that the software products and processes in the product life cycle conform to their specific requirements and adhere to their established plans" [3]. SQA encompasses the complete SDLC, which includes processes such as software design, coding, source code control, code reviews, configuration, and change and release management. SQA not only makes certain that an application is free of errors and defects, but that it is reliable, fully documented, maintainable, and completely functional.

An example is a single course titled 'INFS7550-A Quality Issues Information Technology Project Management', which was put together by one of the researchers. This course examines knowledge, strategies and techniques needed to manage the development of software products. This course is designed to help students develop the skills managers require in order to create and execute plans for software development. Topics include software development life cycles, software development standards, control strategies for software development, software testing strategies, and software metrics. The students work on a semester project weekly with the instructor. Below is information about this project assignment, which can also be injected within this Web-based application:

\section{Final Report Instructions}

Identify five companies listed on NYSE or NASDAQ that carry a value of $\$ 5.00$ or more per-share value. Review each company is Web site, promotional site, or even an open source piece of software and make note of any defect or QA issue that you find.

Document and log the following:

1. What was the issue?

2. The steps you take to replicate the issue and any images or errors to illustrate your support?

3. Document the issue, "bug" or defect for the report.

4. Send it to the company as an issue.

5. Document the response(s) and the processes each organization took.

6. Document if it was fixed or an estimated time to be fixed.

At least three of the five companies you identified with issues ought to communicate back to you. If not find and identify a few other companies until you have a total of three responses back. Document the approach each organization's help desk took to fix the problem. Create a report log of your findings as if you were to present it to the organization's CIO, Project Manager or Director of Quality Assurance. 


\section{Issues in Information Systems}

Volume 14, Issue 1, pp.300-306, 2013

Within the framework for this application, the students were introduced to two market leading software-testing tools, which influence $94 \%$ of its industry. The researcher also used in the class other free and trial software testing tools where the students could easily use as they are conducting this assignment. For instance, for browser security testing, one possible tool is a Quality Browser Check, which students can install its plug-in to test their designed implemented websites.

\section{PHASES}

The following section outlines the phases or steps to be followed. A detailed discussion of particular issues concerning each phase is then provided.

1. Select Project

2. Establish Workgroups

3. Web Application Requirements

4. Web Application Design

5. Software Testing

6. Implement Web Application

7. Student/Site Evaluation

\section{Select Project}

Researchers have explored project-based learning in various disciplines and have generally found it to be effective in increasing student motivation, improving student attitudes toward learning, increasing student problem solving, providing students with an integrated learning situation, addressing different learning styles, and providing growth in self-reliance. Project-based learning motivates the students to do additional work, illustrate to the students the value of the material covered, and most importantly, provides practical experiences that enrich the student's academic experiences. [1, 2, 4, 7]. As a result, the framework described in this paper involves a project-based approach and can involve either a simulated or real world application.

The instructor usually introduces a simulated project and acts as the user. The instructor, the student, the university, or a business can introduce a real world project. Whether a simulated or real world -project is selected it is essential to decide on time management limitations.

A simulated project allows for control over the system requirements by the instructor and most importantly, incomplete projects are not an issue. Examples of simulated projects used by the authors include a fictitious pizza restaurant in which orders can be placed on-line and an on-line store selling selection of clothing.

Conversely, the requirements with a real-world project many times originate with an actual end-user outside of the university. As a result, selecting a real world project necessitates the instructor paying considerable attention to scope and time constraint issues because the students have only a semester to complete the application. It has been the researcher's experience that real-world users can modify the projects requirements and many times forget that they are dealing with students and many times instructors attempting to accomplish too much.

A case in point involved one of the author's experiences in developing a web-based careers site in which companies and candidates could post their new job opportunities and profiles and process the payment by credit card. The time constraints were met at every critical point except for the credit card processing. Given the level of not only student expertise but also the instructors, it was impractical to implement this requirement in the allotted time frame.

\section{Establish Workgroups}

Within this framework, the construction of a Web based application is accomplished as a member of a workgroup or development team. Roles and responsibilities define the functions performed by members of the workgroup, the number of groups is determined by the class size, and the number of project components of the Web-based application determines the size of the group. Experience suggests that an ideal workgroup should be no more than six to eight students 


\section{Issues in Information Systems}

Volume 14, Issue 1, pp.300-306, 2013

All of the students involved with the Web-based application should have completed the prerequisites as indicated previously in this paper. However, some students may be more competent or interested in one functional role or area as oppose to another. For example, a student may be interested in designing the database as opposed to working with the graphics. Another example is that a student may have taken a Multi-Media graphics course as an elective and have well developed skill within this area. To aid the instructors in selecting roles for workgroup members, a competency/preference/interest list can be constructed by the instructor and distributed to the class. The assignment to each group is then based on the results of his document. It should be noted that a students with a high level of competency in one area can be paired with a student not a proficient in that area. This can be a great learning experience for both students.

For example, a breakdown of the roles of a workgroup for the simulated pizza application mentioned previously in the Select Application included nine students with the following roles:

Graphics - one student

Web page designer - one student

Programmers - two students

Database design - three students

Web author/editor - one student

\section{Web Application Requirements}

This phase can closely follow the Analysis phase in the traditional systems development life cycle. Data is collected from the end-user (instructor or real-world) relating to the scope of the project, which includes the purpose and target users as well as the Web server needs in relation to expected site traffic and growth, database requirements, and graphics.

Since information is at the heart of the Web based application, it is important that the database be accurate and dependable. A complete data and work flow analysis should take place with the end-user (instructor or real-world) to identify how the information needs are to be accessed and presented. The students can then normalize the data and create a model for usability testing prior to application development.

Many times the application can have at least two views: the user's view and the administrator's view, which is a password-protected back end for accessing and updating the database. Optionally, the application may require the use of many other features such as file transfers, email generation, a secure socket layer, and possibility video, and animation.

During this phase, each workgroup expresses the system requirements as objectives delivered to the instructor. In other words, the instructor's role is that of a project leader and within this role, feedback is a crucial part of the learning process. The deliverables can define the appearance of each page, navigational links among pages, and details of the database including tables and fields. The document should also contain an implementation plan representing how tasks such as graphic design or database programming are allocated among team members. The entire process should not take more than four weeks.

\section{Web Application Design}

Following the content analysis by each workgroup and the instructor approval of the submitted content, the process of Web site designing can begin. As with the analysis phase, this phase can follow the systems design phase in the traditional systems development life cycle (SDLC). How the design is accomplished is up to each workgroup and the role of the instructor is once again that of a project leader. For example, since a Web-based application should have a universal look or a master/ home page, all members of the workgroup can contribute to this design. In relation to specific content pages, security, graphics, and database design, workgroup members may want to work individually.

It is necessary for the instructor to consider several important issues relating to the design of the Web site pages. 


\section{Issues in Information Systems}

Volume 14, Issue 1, pp.300-306, 2013

For example, to what extent will the instructor permit individual or team creativity? Generally, good Web design requires consistency. One negative side to consistency is the elimination of techniques from the learning process. One way to manage this is to promote consistency via the home page that will carry common elements on all pages created by using layers or tables. Beyond this, each group could be permitted to be creative but maintaining consistency within their group as long as the creativity meets the requirements of the system established in the analysis phase. Each workgroup is required to provide deliverables to the instructor marking progress and the design process should not take more than three weeks.

\section{Software Testing}

A deadline will be set for the completion of the Web-based application approximately two weeks before the end of the semester. The students would have been introduced to market leading software-testing tools in industry as well as free and trial software testing tools. For instance, there are currently two market leading software-testing tools that influence more or less $82 \%$ of software testing industry. One example of this type of tool is for Web Application Security Testing (WAST), using IBM AppScan, "which is an automated web security testing tool that also integrates within the Software Development Life Cycle (SDLC)" [9]. Using "Automated Web Application Security [tools] provides an innovative way to integrate application security, business requirements, application and systems testing within the software development life cycle" [9] for an interactive web-based course curriculum.

\section{Implement Web Application}

Following software testing, all workgroups deploy their respective Web-based projects to the Web server. In the case of a simulated project, the Web server may be the schools, Departments or the instructors. On the other hand, with a real world project, the Web server can be the end user's server that is usually a commercial hosting service. Each group then will document the web site. Tools should be used to assist the process for example implementing a defect tracking, test plan, test execution, and test automation systems will help enhance student interaction and understanding.

\section{Student/Site Evaluation}

Grading for this project is based on all of the deliverables or assignments that are completed in the Requirements, Design, Testing and Implementation phases. Depending upon the complexity of the Web-based application, the number of assignments can vary as well as the points for each assignment. A rubric or checklist can be constructed to keep track of theses assignment so the students are aware of the progress they are making. Of course a number of points can be assignment to the completed Web-based project. However, if the project is not completed due to a problem such as with the credit card processing of the web-based careers site as explained in the Select Application phase, points should not be deducted. This was more the fault of the instructor for not realizing or controlling the scope of the real-world application.

Another item to be graded is the individual's contributions to the workgroup. Many times, several members of a workgroup do most of the work and others do not. The authors have found that rather than having the instructor makes this determination, individual group members will evaluate each other as per an anonymous evaluation sheet constructed by the instructor.

An example of a grade breakdown for one class was as follows:

Deliverables (Assignments) - $70 \%$, Completed Web site $30 \%$, Individual group member assessment $10 \%$.

\section{IMPLEMENTATION OF PREVIOUS PROJECTS}

This course has made use of both simulated and real-word projects. Each project has had no more than five components and no more than six related database tables. As previously referenced the Select Application phase, examples of simulated projects included a fictitious online pizza restaurant and store selling selection of clothing. The real-world example was a web-based careers site in which companies and candidates could post their new job opportunities and profiles and process the payment by credit card. In fact, almost any subject involving a database 


\section{Issues in Information Systems}

Volume 14, Issue 1, pp.300-306, 2013

and the "Shopping Cart" concept can be used with this framework. Other subject areas in which students have implemented projects include: Home Remodeling Business, Beauty Saloon Scheduling System, Fraternity Membership System, and a Wedding Planner System

\section{CONCLUSIONS}

One purpose of the project based framework for an interactive Web-based application is to allow Information Systems students to integrate and apply essential knowledge, skills, and abilities learned in a typical Information Systems program of study. Therefore, this framework is more involved than just teaching students how to create web pages and posting them to the Internet. It should serve as practical guides to enable students to work in a team environment and apply not only their subject based knowledge in Information Systems but also develop their communication and team work skills.

If one of the objectives of an academic program is to produce systems, then it seems that at some point in their studies a student must experience this concept first hand. The described framework produces a system related to a topic in high demand, bolsters student confidence, provides an excellent focus for discussions in interviews with prospective employers, and enables students to participate in an actual group project. This is completed while experiencing all the problems associated with group dynamics, and demonstrates the difficulty and importance of working with a demanding time schedule.

\section{REFERENCES}

1. Albanese, M. \& Mitchell, S. (1993). Problem-based learning: A review of literature on its outcomes and implementation issues. Academic Medicine, 68(1), 52-81.

2. Edutopia. (2012). Why is Project-based Learning Important? Retrieved April 9, 2013, from http://www.edutopia.org/project-based-learning-guide-importance.

3. Feldman, S. (2005). Quality Assurance: Much More than Testing. Retrieved March 10, 2013, from Association from Association for Computing Machinery: http://queue.acm.org/detail.cfm?id=1046943

4. Hutchings, P. and A. Wutzdorff, (1988), "Experimental learning across the curriculum: Assumptions and principals." New Directions for Teaching and Learning, 35, 5-19.

5. Schulmeyer, G., \& McManus, J.I. (1999). Guide to Software Quality Assurance. (pp.7) New Jersey: Prentice Hall PTR.

6. Seyed-Abbassi Behrooz, (2002) "The Evolution of an Advanced Database Course in an Information Systems Curriculum" ISECON 2002 19th Annual Conference on Information Systems Education.

7. Tretten, R. \& P., Zachariou, (1995), "Learning about project based learning." Paper prepared for the Autodesk Foundation, San Rafael, CA.

8 W3Techs. (2013). Usage of server-side programming languages for websites. Retrieved April 8, 2013, from http://w3techs.com/technologies/overview/programming language/all

9 Laverty, J. and Scarpino, J. (2009). Web Application Security Instructional Paradigms and the IS Curriculum. Issues in Information Systems, Volume X, No. 1, 87-96. 